\title{
Comportamento morfofisiológico da mamoneira BRS Energia submetida à irrigação com água salina ${ }^{1}$
}

\author{
João B. dos Santos², Delfran B. dos Santos ${ }^{3}$, Carlos A. V. de Azevedo', \\ Alex M. Rebequi ${ }^{5}$, Lourival F. Cavalcante ${ }^{5}$ \& Ítalo H. L. Cavalcante ${ }^{6}$
}

\begin{abstract}
RESUMO
Um experimento foi conduzido na estação experimental de Irrigação e Drenagem do Instituto Federal Baiano, para avaliar o crescimento da mamoneira BRS Energia, em função da salinidade da água de irrigação, em sistema de lisimetria. Os tratamentos foram constituídos dos níveis de salinidade da água de 0,$12 ; 0,8 ; 1,6 ; 2,4 ; 3,2 ; 4,0$ e 4,8 dS m m$^{-1}$, dispostos em delineamento inteiramente casualizado, com três repetições e quatro plantas por tratamento. Quinzenalmente foram avaliados, dos 20 até os 80 dias após a emergência, o crescimento e as taxas de crescimento absoluto e relativo da altura de plantas, diâmetro do caule e a área foliar das plantas. O crescimento avaliado pela altura, diâmetro do caule, área foliar e as taxas de crescimento absoluto e relativo de cada variável, diminuíram com o aumento da salinidade da água de irrigação, em todos os períodos estudados. As inibições foram respostas da elevação do nível salino do solo de não salino, para ligeiramente, moderadamente e fortemente salino.
\end{abstract}

Palavras-chave: Ricinus communis, água de qualidade inferior, biodiesel

\section{Morphophysiological behavior of castor bean BRS Energia submitted to irrigation with saline water}

\begin{abstract}
An experiment was conducted at the experimental station of Irrigation and Drainage of the Instituto Federal Baiano, to evaluate the growth variables of the castor bean BRS Energia as a function of salinity of irrigation water in lysimeters. The treatments were constituted of water salinity levels of $0.12 ; 0.8 ; 1.6 ; 2.4 ; 3.2 ; 4.0$ and $4.8 \mathrm{dS} \mathrm{m}^{-1}$, disposed in a completely randomized design, with three replications and four plants per treatment. Fortnightly from 20 to 80 days after emergence, the growth variables and the absolute and relative growth rates of plant height, stem diameter and leaf area of plants were evaluated. The growth measured by height, stem diameter, leaf area and the rates of absolute and relative growth of each variable, decreased with increase in irrigation water salinity in all periods. The restrictions were in response to increase in soil salinity levels from non saline soil to slightly, moderately and strongly saline soil.
\end{abstract}

Key words: Ricinus communis, water of inferior quality, biodiesel

\footnotetext{
1 Parte da tese de doutorado do primeiro autor apresentada a UFCG

${ }^{2}$ UAEA/UFCG, Av. Aprígio Veloso, 882, Bodocongó, CEP 58109-970, Campina Grande, PB. Fone: (83) 9951-3021. E-mail: agrosantos@hotmail.com

${ }^{3}$ IF Baiano/Campus de Senhor do Bonfim, Km 4 da Estrada da Igara, s/n, Zona Rural, CEP 48970-000, Senhor do Bonfim, BA. Fone: (74) 3541-3676. E-mail: delfran.batista@gmail.com

${ }^{4}$ UAEA/UFCG. Fone: (83) 2101-1056. E-mail: cazevedo@deag.ufcg.edu.br

${ }^{5}$ PVNS-CAPES/CCTA/UFCG, CEP 58840-000, Pombal, PB. Fone: (83)3431-4016E-mail: lourival.cavalcante@ccta.ufcg.edu.br;lofeca@cca.ufpb.br

${ }^{6}$ UFPI, BR 135, Km 3, s/n, CEP 64900-000, Bom Jesus, PI. Fone: (89) 3562-1866. E-mails:italohlc@ufpi.edu.br
} 


\section{INTRODUÇÃO}

Com o advento do Programa Nacional de Biodiesel visando à adição de $2 \%$ de biodiesel (B2) ao diesel, em 2005, diversos Estados do Nordeste receberam incentivos financeiros do governo federal para expandir a área de exploração de mamona, embasada principalmente na agricultura familiar (Beltrão et al., 2010). Esses incentivos têm, como metas, a produção e a extração do óleo das sementes, por se tratar de um importante subproduto para a economia do País, contribuindo para a melhoria da qualidade do meio ambiente, pela redução do índice de poluição do ar e pela diminuição da dependência pelo petróleo (Santos et al., 2011). Em função principalmente desses importantes aspectos e também do uso da torta de mamona como fertilizante orgânico, é que se buscam informações técnicas e científicas sobre o desempenho vegetativo e produtivo da mamoneira (Ricinus communis L.) nas áreas semiáridas do Brasil (Lima et al., 2011).

O monitoramento do comportamento vegetativo, do plantio ao início da floração ou da frutificação, das plantas em geral, inclusive da mamoneira, constitui uma etapa imprescindível para a tomada de decisões sobre a forma de manejo da irrigação e da adubação da cultura (Rios et al., 2011; Mesquita et al., 2012). Neste contexto, uma das primeiras observações se refere à homogeneidade das plantas, em termos de crescimento em altura, diâmetro caulinar, emissão das folhas, área foliar; enfim, dos atributos morfológicos e fisiológicos das plantas sob condições de estresse salino (Cavalcanti et al., 2005a) ou outro tipo de estresse como condição física do solo, deficiência hídrica à cultura ou poda das plantas (Taherifard \& Farzad, 2011).

Apesar de a mamoneira resistir à deficiência de água no solo sem perdas marcantes do crescimento e ser moderadamente tolerante aos sais (Babita et al., 2010) associada à sua rusticidade em se adaptar à maioria dos solos da Região Nordeste, seu cultivo nas áreas semiáridas do Brasil com viabilidade econômica às metas propostas pelo Programa Nacional de Biodiesel, depende da irrigação (Cavalcanti et al., 2008; Centeno et al., 2012). Entretanto, na maior parte dessas áreas, além da irregularidade das chuvas, a qualidade das águas dos mananciais de superfície e subterrâneos é constituída, quase sempre, de salinidade superior aos níveis tolerados pela maioria das plantas cultivadas, inclusive a mamoneira (Campos et al., 2009).

As exigências mundiais estão aumentando bruscamente, não só pela produção de alimentos e de produtos de origem animal e vegetal para consumo da humanidade mas estão crescendo também, nas mesmas proporções, as necessidades por fontes alternativas de energia das mais variadas formas, dentre as quais se inserem os biocombustíveis que têm, como suprimento alternativo de matéria-prima, a agricultura. Neste sentido e pela reduzida oferta de água de boa qualidade que atenda à atividade agrícola, o consumo humano, animal e industrial, um dos recursos propostos é o emprego de águas de qualidade restritiva quanto aos sais na agricultura. Entretanto, isto não significa sugerir nem adotar o uso de água do mar ou de nível equivalente de sais na produção agrícola (Rhoades et al., 2000; Medeiros et al., 2010).

Ao considerar que a exploração de muitas culturas nas áreas semiáridas, dentre as quais a mamoneira, que é moderadamente sensível aos sais (Ayers \& Westcot, 1999; Silva et al., 2008) pode ser comprometida pelo acúmulo de sais no solo pela irrigação; ao considerar também que as águas dessas respectivas áreas são, quase sempre, de qualidade restritiva à mamoneira (Cavalcanti et al., 2005a; Lima et al., 2007) e outras culturas não alimentícias como nim-Azdirachta indica (Holanda et al., 2007; Freire et al., 2010), noni-Morinda citrifolia (Nunes et al., 2009; Nivas et al., 2011); pinhão manso-Jatropha curcas (Nery et al., 2009; Veras et al., 2011) estratégias de manejo devem ser adotadas para que se possa aplicar águas moderadamente salinas, de condutividade elétrica acima de 2 e $3 \mathrm{dS} \mathrm{m}^{-1}$, na produção agrícola.

Nesta direção uma das alternativas é a lavagem periódica do solo com a própria água de irrigação para que ocorra lixiviação dos sais do ambiente radicular das plantas e possibilite o uso de águas salinas na agricultura. Ante o exposto, o trabalho teve como objetivo avaliar o crescimento da mamoneira BRS Energia irrigada com águas de salinidade crescente desenvolvida em lisímetro de drenagem.

\section{Material e Métodos}

O experimento foi conduzido de setembro de 2008 a janeiro de 2009, utilizando-se lisímetros de drenagem instalados em uma área de $124,6 \mathrm{~m}^{2}$ com $7 \mathrm{~m}$ de largura e $17,8 \mathrm{~m}$ de comprimento pertencente à estação experimental de Irrigação e Drenagem do Instituto Federal Baiano, Campus de Senhor do Bonfim, BA, localizada nas coordenadas $10^{\circ} 28^{\prime} \mathrm{S}, 40^{\circ} 11^{\prime}$ W e altitude de $455 \mathrm{~m}$.

Os lisímetros foram constituídos por caixas de fibra de vidro com volume de $1.120 \mathrm{~L}$, largura de $1 \mathrm{~m}$, comprimento de $1,4 \mathrm{~m}$ e profundidade de $0,80 \mathrm{~m}$. O espaçamento das fileiras e das plantas nos lisímetros foi de 0,7 e $0,5 \mathrm{~m}$, respectivamente. Os lisímetros foram instalados a uma profundidade de 0,75 $\mathrm{m}$ do solo; na base de cada um foi feito um orifício ao qual se conectou uma tubulação para levar o efluente drenado aos recipientes coletores. $\mathrm{Na}$ face do orifício, localizada na parte interna do lisímetro, foi instalada uma calha de $30 \mathrm{~cm}$ de comprimento, feita em tubo de PVC com diâmetro de 33 $\mathrm{mm}$; após sua instalação foram colocadas uma camada de brita número zero com espessura de $2 \mathrm{~cm}$, uma camada de areia lavada de igual espessura e, por fim, camada de solo; o solo foi colocado em camada de $10 \mathrm{~cm}$ para manter a densidade global próxima da original do solo, até atingir a altura de $60 \mathrm{~cm}$ de solo.

O solo utilizado para o preenchimento dos lisímetros foi um Latossolo Amarelo eutrófico típico existente na estação experimental do Instituto Federal Baiano, de Senhor do Bonfim. Preenchidos os lisímetros foram coletadas amostras simples de solo nas camadas de 0-20 e 20-40 cm de profundidade em cada lisímetro, para formar uma amostra composta caracterizada físico-quimicamente (Tabela 1) de acordo com a metodologia descrita pela EMBRAPA (1997).

O experimento foi conduzido sob delineamento experimental inteiramente casualizado, com sete tratamentos e três repetições, totalizando 21 parcelas, cada uma composta por um lisímetro de drenagem. Os tratamentos foram sete níveis de salinidade da água de irrigação: 0,$12 ; 0,8 ; 1,6 ; 2,4 ; 3,2 ; 4,0$ e 4,8 dS m${ }^{-1}$ a $25{ }^{\circ} \mathrm{C}$. O nível mais baixo de salinidade da água corresponde 
Tabela 1. Características físico-químicas nas camadas de 0-20 e 20-40 cm de profundidade do solo coletado no interior dos lisímetros, antes da aplicação dos tratamentos

\begin{tabular}{|c|c|c|}
\hline \multirow{2}{*}{ Característica } & \multicolumn{2}{|c|}{ Camada (cm) } \\
\hline & $0-20$ & 20-40 \\
\hline $\begin{array}{l}\text { Química } \\
\text { pH } \\
\text { MO }\left(\mathrm{g} \mathrm{kg}^{-1}\right) \\
\mathrm{P}\left(\mathrm{mg} \mathrm{dm}^{-3}\right) \\
\mathrm{Ca}^{2+}\left(\mathrm{cmol}_{\mathrm{c}} \mathrm{kg}^{-1}\right) \\
\mathrm{Mg}^{2+}\left(\mathrm{cmol}_{\mathrm{c}} \mathrm{kg}^{-1}\right) \\
\mathrm{K}^{+}\left(\mathrm{cmol}_{\mathrm{c}} \mathrm{kg}^{-1}\right) \\
\mathrm{Na}^{+}\left(\mathrm{cmol}_{\mathrm{c}} \mathrm{kg}^{-1}\right) \\
\mathrm{Al}^{3+}\left(\mathrm{cmol}_{\mathrm{c}} \mathrm{kg}^{-1}\right) \\
\mathrm{H}^{+}+\mathrm{Al}_{3+}\left(\mathrm{cmol}_{\mathrm{c}} \mathrm{kg}^{-1}\right) \\
\mathrm{SB}\left(\mathrm{cmol}_{\mathrm{c}} \mathrm{kg}^{-1}\right) \\
\text { CTC }\left(\mathrm{cmol}_{\mathrm{c}} \mathrm{kg}^{-1}\right) \\
\text { V (\%) } \\
\left.\text { CEes (dS m}{ }^{-1}\right) \\
\text { PST (\%) }\end{array}$ & $\begin{array}{r}6,50 \\
15,50 \\
136,00 \\
2,80 \\
1,98 \\
0,31 \\
0,16 \\
0,01 \\
2,36 \\
5,25 \\
7,61 \\
68,90 \\
0,71 \\
2,18\end{array}$ & $\begin{array}{r}6,30 \\
11,90 \\
51,50 \\
2,10 \\
1,61 \\
0,23 \\
0,13 \\
0,01 \\
2,03 \\
4,07 \\
6,10 \\
66,70 \\
0,76 \\
2,21\end{array}$ \\
\hline $\begin{array}{l}\text { Física } \\
\text { Areia }\left(\mathrm{g} \mathrm{kg}^{-1}\right) \\
\text { Silte }\left(\mathrm{g} \mathrm{kg}^{-1}\right) \\
\text { Argila }\left(\mathrm{g} \mathrm{kg}^{-1}\right) \\
\text { Ada }\left(\mathrm{g} \mathrm{kg}^{-1}\right) \\
\text { GF }(\%) \\
\text { Índice de dispersão (\%) } \\
\text { Ds }\left(\mathrm{g} \mathrm{cm}^{-3}\right) \\
\text { Dp }\left(\mathrm{g} \mathrm{cm}^{-3}\right) \\
\text { Pt }\left(\mathrm{m}^{3} \mathrm{~m}^{-3}\right)\end{array}$ & $\begin{array}{r}731,00 \\
75,00 \\
194,00 \\
106,00 \\
45,60 \\
54,40 \\
1,21 \\
2,53 \\
0,52\end{array}$ & $\begin{array}{r}698,00 \\
79,00 \\
223,00 \\
127,00 \\
43,10 \\
56,90 \\
1,35 \\
2,53 \\
0,47\end{array}$ \\
\hline
\end{tabular}

CEes - Condutividade elétrica do extrato de saturação; CTC - Capacidade de troca catiônica - [SB + $\left(\mathrm{H}^{+}\right.$ $+\mathrm{Al}^{3+}$ )]; M0 - Matéria orgânica; PST - Percentagem de sódio trocável $\left(\mathrm{Na}^{+} / \mathrm{CTC}\right) 100$; SB - Soma de bases $\left(\mathrm{Ca}^{2+}+\mathrm{Mg}^{2+}+\mathrm{K}^{+}+\mathrm{Na}^{+}\right) ; \mathrm{V}$ - Saturação por bases $=(\mathrm{SB} / \mathrm{CTC}) \times 100 ;$ Ada - Argila dispersa em água; Ds - Densidade do solo; Dp - Densidade de partícula; GF - Grau de floculação (Argila - Ada/ argila $)^{\star} 100 ;$ Pt - Porosidade total $\left(1-\left((\mathrm{Ds} / \mathrm{Dp})^{\star} 100\right)\right.$

à água fornecida pela Empresa Baiana de Água e Saneamento (EMBASA) (Tabela 2). Os demais níveis de salinidade foram obtidos adicionando-se cloreto de sódio, cloreto de cálcio e cloreto de magnésio, nas proporções equivalentes de 7:2:1 respectivamente, na água da EMBASA. Cada unidade experimental (lisímetro) foi ocupada por quatro plantas de mamona da cultivar BRS Energia, totalizando 84 plantas úteis no experimento.

A avaliação do crescimento da mamoneira foi realizada quinzenalmente, dos 20 até os 80 dias após emergência (DAE) medindo-se, nas quatro plantas de cada lisímetro, a altura de planta do colo até o meristema apical da planta, utilizando-se uma trena milimetrada; o diâmetro do caule foi medido por um paquímetro digital a $1,0 \mathrm{~cm}$ do solo e a área foliar obtida pela metodologia proposta por Severino et al. (2004) conforme a Eq. 1:

$$
\sum \mathrm{S}=0,2622 \times \mathrm{P}^{2,4248}
$$

em que:
$\Sigma \mathrm{S}$ - área foliar total, $\mathrm{cm}^{2}$

P - comprimento da nervura principal da folha, $\mathrm{cm}$

A partir dos valores médios quinzenais de altura de planta, diâmetro de caule e área foliar, foram calculadas suas respectivas taxas de crescimento absoluto (TCA) e taxas de crescimento relativo (TCR) conforme as Eqs. 2 e 3 (Benincasa, 2003):

$$
\begin{gathered}
\text { TCA }=\frac{V_{2}-V_{1}}{t_{2}-t_{1}} \\
\text { TCR }=\frac{\ln \left(V_{2}-V_{1}\right)}{t_{2}-t_{1}}
\end{gathered}
$$

em que:

TCA - taxa de crescimento absoluto

TCR - taxa de crescimento relativo

ln - logaritmo natural

$\mathrm{V}_{1}$ - crescimento da planta no tempo $\mathrm{t}_{1}$

$V_{2}$ - crescimento da planta no tempo $t_{2}$

Os valores médios de crescimento em altura de plantas, diâmetro do caule e área foliar em função da salinidade da água de irrigação, foram analisados isoladamente em cada tempo avaliado (20,35, 50, 65 e 80 DAE). Para isto, os valores médios foram submetidos à análise de variância e, quando pertinente, à regressão polinomial (Banzatto \& Kronka, 2006). As taxas de crescimento absoluto e relativo de altura de plantas, diâmetro do caule e área foliar, foram analisadas em parcela subdividida mantendo-se, na parcela, os níveis de salinidade da água de irrigação e, na subparcela, o tempo de avaliação ressaltando-se que, quando pertinente, os valores médios foram comparados por regressão.

\section{Resultados E Discussão}

O aumento da condutividade elétrica das águas inibiu linearmente o crescimento das plantas em altura aos níveis de $-8,40,-10,33$ e $-10,65 \mathrm{~cm}$, para cada aumento unitário da salinidade da água durante todo o ciclo da mamoneira, avaliado aos 50, 65 e 80 respectivamente (Figura 1). Constatou-se, também, efeito significativo linear decrescente, a 0,01 de probabilidade, em função do aumento da salinidade da água de irrigação na altura de plantas aos 20 e 35 dias após emergência da mamoneira, embora os coeficientes de determinação tenham ficado abaixo de 0,60 (equação de regressão $\mathrm{AP}_{20}=$ $-1,51 * * \mathrm{CEa}+33,53$ e $\mathrm{R}^{2}=0,38$; equação de regressão $\mathrm{AP}_{35}=$ $-3,38 * * \mathrm{CEa}+63,88$ e $\left.\mathrm{R}^{2}=0,56\right)$. Ao relacionar os valores entre as plantas irrigadas com a água de maior e de menor nível salino constatam-se reduções de 27,5; 28,1 e 29,2\% respectivamente

\begin{tabular}{|c|c|c|c|c|c|c|c|c|c|}
\hline \multirow{2}{*}{ pH } & $\mathrm{Ca}^{2+}$ & $\mathrm{Mg}^{2+}$ & $\mathrm{Na}^{+}$ & $\mathrm{K}^{+}$ & Carbonato & Bicarbonato & $\mathrm{Cl}^{-}$ & \multirow{2}{*}{$\begin{array}{c}\text { RAS } \\
\left(\mathrm{mmol}_{\mathrm{G}} \mathrm{L}^{-1}\right)^{0,5}\end{array}$} & \multirow{2}{*}{$\begin{array}{l}\text { CEa } \\
\mathrm{dS} \mathrm{m}^{-}\end{array}$} \\
\hline & & & & $\mathrm{mmol}_{\mathrm{G}} \mathrm{L}^{-1}$ & & & & & \\
\hline
\end{tabular}
aos 50, 65 e 80 DAE.

Tabela 2. Características químicas da água da EMBASA

RAS - Razão de adsorção de sódio $\mathrm{Na}^{+}\left\{\left[\left(\mathrm{Ca}^{2+}+\mathrm{Mg}^{2+}\right) / 2\right]^{-1}\right\}^{0,5}$; $\mathrm{CEa}$ - Condutividade elétrica da água 


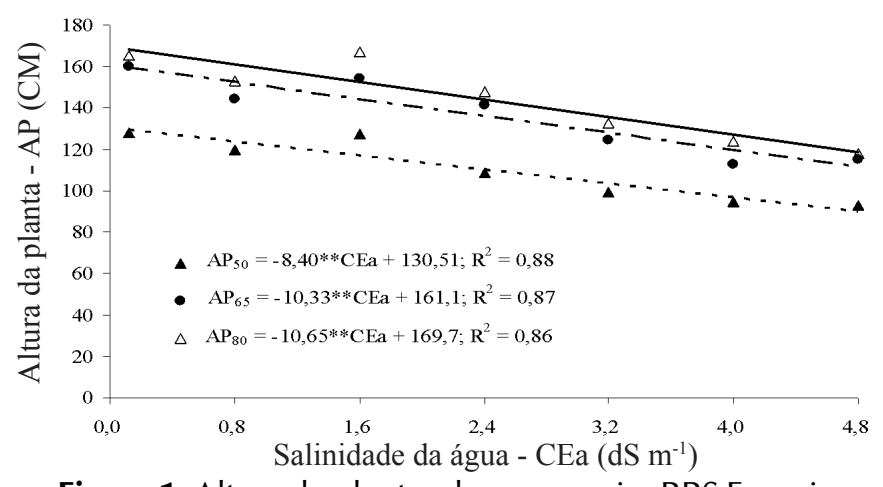

Figura 1. Altura de plantas da mamoneira BRS Energia irrigada com águas salinas aos 50, 65 e 80 DAE

As perdas verificadas expressam o caráter moderadamente sensível da mamoneira à salinidade da água ou do solo, conforme apresentado em Ayers \& Westcot (1999) e evidenciam aumento da sensibilidade ao longo do crescimento das plantas até a floração, formação e maturação dos frutos. Por outro lado, os resultados da relação entre os dados obtidos aos 80 e 20 DAE indicam que as plantas, mesmo quando irrigadas com águas de teor salino elevado em relação ao valor tolerado pela cultura, continuaram crescendo aos níveis de 429, 409, 337, 394, 393, 360 e $351 \%$. Comparativamente com plantas da mesma família, as tendências são semelhantes às registradas por Cavalcanti et al. (2005b), Lima et al. (2007) e Campos et al. (2009) após irrigarem mamoneira, e por Freire et al. (2010) e Nivas et al. (2011) em plantas de nim e de noni sob irrigação com águas salinas.

$\mathrm{O}$ diâmetro do caule, tal como o crescimento em altura, diminuiu com o incremento salino das águas em qualquer data avaliada após a emergência. As irrigações das plantas com as respectivas águas provocaram perdas de $-0,55,-1,27,-2,16$, $-2,51$ e $-2,45 \mathrm{~mm}$, relativas a cada aumento unitário do teor salino das águas, da semeadura aos $20,35,50,65$ e 80 DAE, que correspondem às reduções de $21,27,33,32$ e $32 \%$ entre as plantas irrigadas com águas de maior e de menor condutividade elétrica (Figura 2). Constata-se ainda, como na altura, que apesar da inibição devida ao aumento da condutividade elétrica das águas, as plantas apresentaram, em geral, diâmetros crescentes no período de 20 aos 80 DAE quando irrigadas com cada tipo

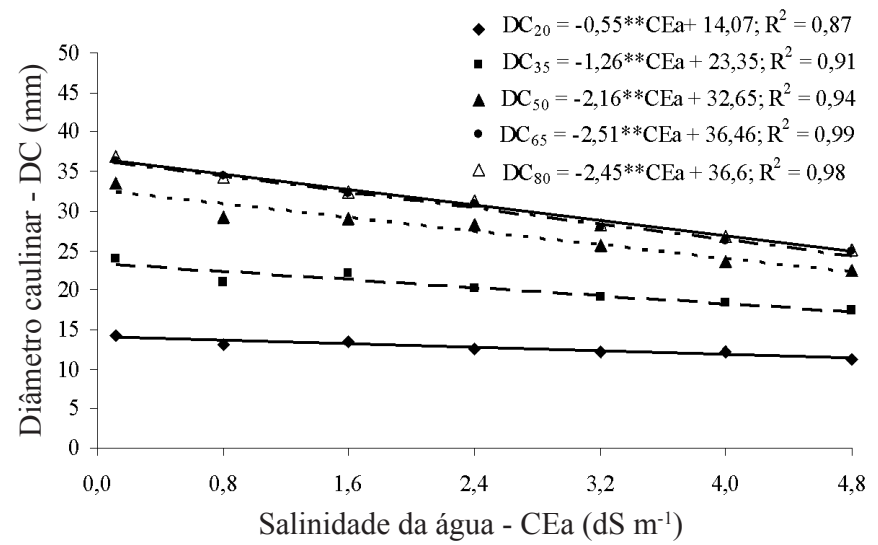

Figura 2. Diâmetro caulinar da mamoneira BRS Energia irrigada com águas salinas, aos 20, 35, 50, 65 e 80 DAE de água, conforme os incrementos de 157, 161, 138, 149, 131, 120 , e $122 \%$. O comportamento do diâmetro caulinar confirma o caráter moderadamente sensível da cultura aos sais avaliados no crescimento em altura e está em coerência com o obtido por Cavalcanti et al. (2005a) e Silva et al. (2008) para a mamoneira BRS Energia e por Nery et al. (2009) para o pinhão-manso, ao concluírem que a irrigação com águas de salinidade acima de $2 \mathrm{dS} \mathrm{m}^{-1}$ prejudica o desenvolvimento de ambas as culturas.

A exemplo do crescimento avaliado pela altura e diâmetro caulinar, o aumento da concentração salina das águas também comprometeu a expansão da área foliar da mamoneira (Figura 3). As reduções foram de $-184,-585,-584,-583$ e $-594 \mathrm{~cm}^{2}$ para cada aumento unitário da condutividade elétrica das águas de irrigação resultando em perdas entre as plantas irrigadas com águas de 4,8 e $0,15 \mathrm{dS} \mathrm{m}^{-1}$ de $48,53,43,42$ e $43 \%$ respectivamente, aos 20,35, 50, 65, e 80 DAE. Entretanto, como observado para o crescimento em altura e o diâmetro percebe-se, pela relação entre os valores medidos aos 80 e 20 DAE, que a área foliar das plantas, mesmo irrigadas com a água de maior teor salino, aumentou a níveis de 212, 224, 271, 255, 222,202 e $244 \%$.

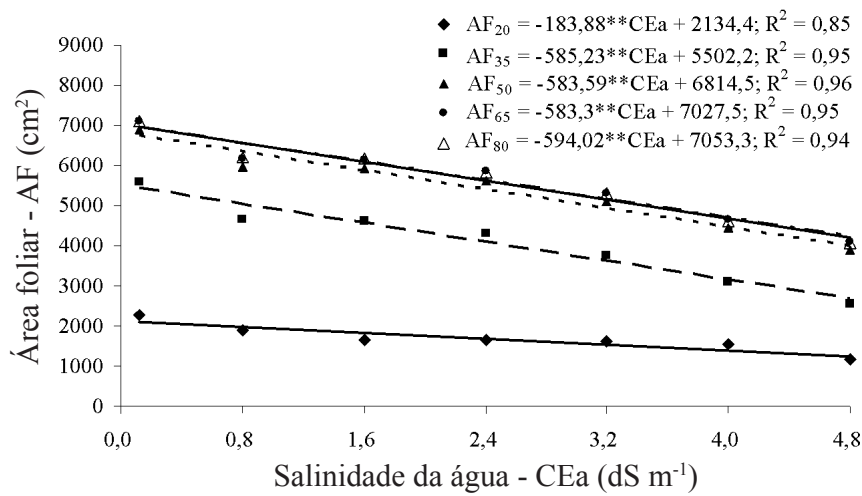

Figura 3. Área foliar da mamoneira BRS energia irrigada com águas salinas, aos 20,35, 50, 65 e 80 DAE

Em função do estresse salino das águas, a redução da área foliar reflete na perda da absorção equilibrada de água e nutrientes pelas plantas cultivadas em geral, inclusive da mamoneira, como comentado por Centeno et al. (2012) e de acordo com Marschiner (2005) quando absorvem a água e ela está mais concentrada em sais, resultando em desbalanço nutricional. Este desequilíbrio pode provocar perdas da produção de fotoassimilados vitais dentre os quais açúcares, carboidratos, proteínas, como apresentado por Silva et al. (2009) após submeterem plantas de pinhão-manso a irrigação com águas salinas.

Os valores crescentes do crescimento em altura, diâmetro caulinar e área foliar das plantas dos 20 aos 80 DAE, mesmo admitindo as perdas com o aumento do teor salino das águas, evidenciam a importância de se adicionar um valor de $10 \%$ ou mais à da lâmina de irrigação (Ayers \& Westcot, 1999). Esta prática promove a lixiviação dos sais por fluxo de massa do ambiente das raízes, mantém o solo mais úmido e, pela ação diluidora mitiga os efeitos degenerativos da salinidade da água ao solo e às plantas. 
Numa comparação entre os valores quantificados em plantas irrigadas com a água de maior e de menor condutividade elétrica constata-se, para cada período avaliado após a emergência, que a área foliar foi o órgão da mamoneira mais comprometido pelo aumento da salinidade das águas. Tendência semelhante foi apresentada também por Cavalcanti et al. (2005b), Lima et al. (2007), Silva et al. (2008) após irrigação da mamoneira com águas salinas.

A taxa de crescimento absoluto em altura de plantas diminuiu com o aumento da salinidade da água durante todos os períodos avaliados (Figura 4). A menor taxa de crescimento em altura de $-3,43 \mathrm{~cm} \mathrm{~d}^{-1}$, foi obtida no tempo 4 (Intervalo de tempo entre 80 e $65 \mathrm{DAE}$ ) na água salina de $4,8 \mathrm{dS} \mathrm{m}^{-1}$ enquanto a maior taxa de $2,77 \mathrm{~cm} \mathrm{~d}^{-1}$ foi registrada no tempo 1 (Intervalo de tempo entre 35 e $20 \mathrm{DAE})$. Entre a maior $\left(2,77 \mathrm{~cm} \mathrm{~d}^{-1}\right)$ e a menor $\left(-3,43 \mathrm{~cm} \mathrm{~d}^{-1}\right)$ taxa de crescimento absoluto em altura de plantas estimadas, houve redução da altura de plantas de 6,2 $\mathrm{cm} \mathrm{d}^{-1}$, sempre que o tempo de cultivo e a salinidade da água de irrigação aumentaram.

Para a taxa de crescimento relativo de altura de plantas não houve efeito significativo da interação salinidade da água

A.

$$
\begin{gathered}
\mathrm{Y}=-5,61-0,35 \mathrm{~S}+0,35 \mathrm{~T}-0,0035 \mathrm{~T}^{2}+0,0034 \mathrm{~S} . \mathrm{T} \\
\mathrm{R}^{2}=0,77
\end{gathered}
$$

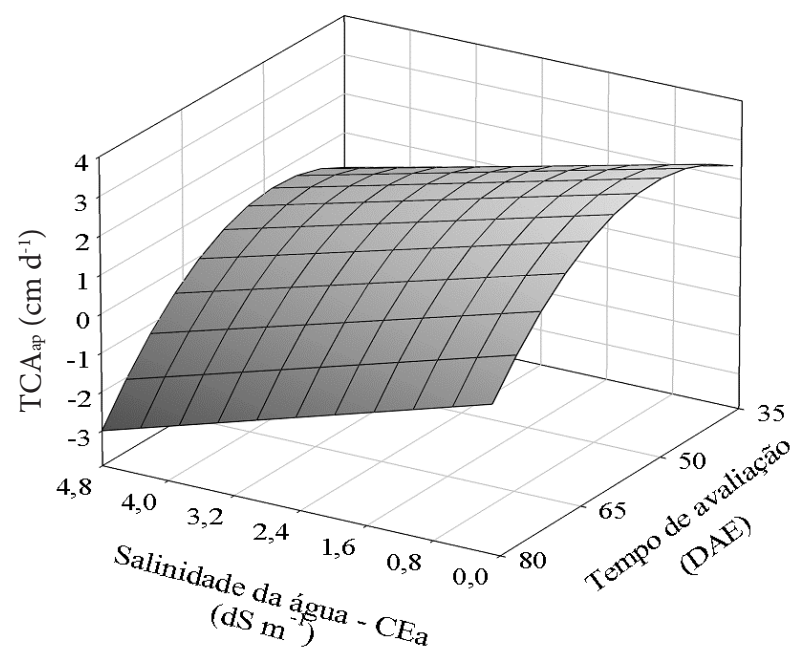

B.

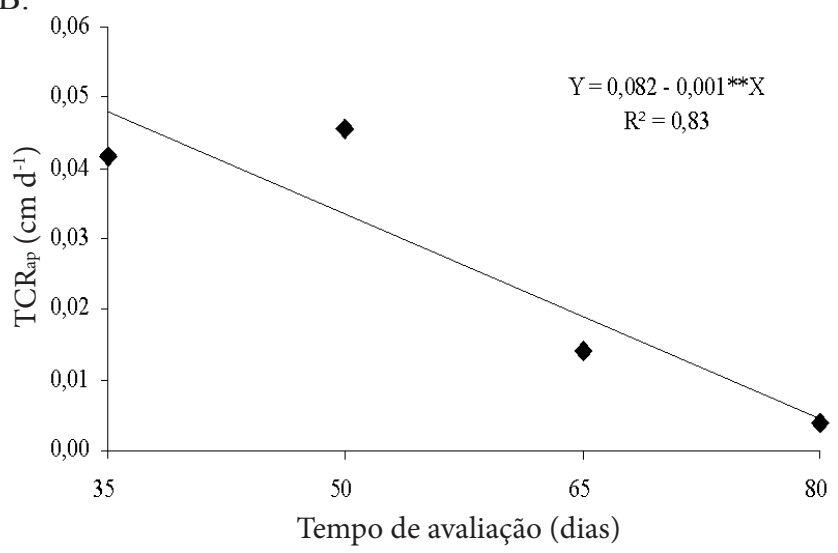

Figura 4. Taxa de crescimento absoluto- $\mathrm{TCA}_{\mathrm{ap}}(\mathrm{A})$ e relativo - $\mathrm{TCR}_{\mathrm{ap}}$ (B) em altura de plantas, em função do tempo de crescimento da mamoneira irrigada com águas salinas versus tempo de cultivo porém se constatou efeito significativo para o tempo de cultivo (Figura 4B). A equação ajustada aos valores médios da taxa de crescimento relativo de altura de plantas em função do tempo de cultivo indica uma redução de $0,01 \mathrm{~cm} \mathrm{~cm}^{-1} \mathrm{~d}^{-1}$. As diminuições observadas para a taxa de crescimento absoluto (Figura 4A) e relativo (Figura 4B) são oriundas do menor crescimento vegetativo ocasionado pelas distintas fases de crescimento e desenvolvimento da mamoneira e, principalmente, à ação depressiva dos sais ao metabolismo da planta.

Em geral, a taxa de crescimento absoluto do diâmetro do caule diminuiu com os níveis de salinidade da água de irrigação (Figura 5A). Em função do tempo de avaliação verifica-se que a taxa de crescimento absoluto diminuiu do tempo 1 (intervalo de tempo entre 35 e $20 \mathrm{DAE}$ ) para o tempo 4 (intervalo de tempo entre 80 e $65 \mathrm{DAE})$ na água de menor conteúdo salino $(0,12 \mathrm{dS}$ $\left.\mathrm{m}^{-1}\right)$ enquanto na água de maior conteúdo salino $\left(4,8 \mathrm{dS} \mathrm{m}^{-1}\right)$ a taxa de crescimento absoluto em diâmetro do caule aumentou do tempo 1 para o tempo 4 . A maior $\left(2,95 \mathrm{~mm} \mathrm{~mm}^{-1} \mathrm{~d}^{-1}\right)$ e menor $\left(0,006 \mathrm{~mm} \mathrm{~mm}^{-1} \mathrm{~d}^{-1}\right)$ taxas de crescimento absoluto em diâmetro caulinar foram verificadas no tempo 4 nas águas de maior $(4,8$ $\left.\mathrm{dS} \mathrm{m}^{-1}\right)$ e menor $\left(0,12 \mathrm{dS} \mathrm{m}^{-1}\right)$ salinidade (Figura $\left.5 \mathrm{~A}\right)$.

A taxa de crescimento relativo em diâmetro do caule diminuiu durante o tempo de avaliação, independentemente do conteúdo salino da água de irrigação (Figura 5B). A taxa de crescimento relativo também diminuiu da água de menor para a de maior salinidade no tempo 1 enquanto no tempo 4 a taxa de crescimento relativo do diâmetro do caule nas águas de mesmo conteúdo salino, permaneceu constante. A maior taxa de crescimento relativo em diâmetro do caule de $0,03 \mathrm{~mm} \mathrm{~mm}^{-1}$ $\mathrm{d}^{-1}$ foi obtida no tempo 1 , na água de menor conteúdo salino $\left(0,12 \mathrm{dS} \mathrm{m}^{-1}\right)$ enquanto no mesmo período, porém na água de maior salinidade, a taxa de crescimento do diâmetro do caule foi de $0,02 \mathrm{~mm} \mathrm{~mm}^{-1} \mathrm{~d}^{-1}$ (Figura 5B).

A taxa de crescimento absoluto da área foliar da mamoneira, tal como a da altura de plantas, diminuiu com o aumento do tempo de cultivo e da salinidade da água de irrigação (Figura 6A). A maior taxa de crescimento absoluto da área foliar com valor estimado de $194 \mathrm{~cm}^{2} \mathrm{~d}^{-1}$, obtida no tempo 1 (Intervalo de tempo entre 35 e $20 \mathrm{DAE}$ ) sob a água de menor conteúdo salino $\left(0,12 \mathrm{dS} \mathrm{m}^{-1}\right)$ é $477 \%$ superior à menor taxa de crescimento absoluto da área foliar de $-51,4 \mathrm{~cm}^{2} \mathrm{~d}^{-1}$, obtida no tempo 4 (Intervalo de tempo entre 80 e $65 \mathrm{DAE}$ ) com a água de maior conteúdo salino $\left(4,8 \mathrm{dS} \mathrm{m}^{-1}\right)$.

Apesar de sofrer efeito significativo da interação salinidade da água versus tempo de cultivo, a taxa de crescimento relativo da área foliar não se ajustou a um modelo de regressão. Deste modo, o crescimento relativo da área foliar foi ajustado em função do tempo de cultivo $(p \geq 0,01)$ (Figura 6B). A taxa de crescimento relativo da área foliar diminuiu em função do tempo de cultivo, sendo estimada no tempo 4 uma taxa de crescimento negativo de $0,01 \mathrm{~cm}^{2} \mathrm{~cm}^{-2} \mathrm{~d}^{-1}$. As reduções nas taxas de crescimento relativo da área foliar se devem principalmente ao efeito prejudicial do excesso de sais no metabolismo das plantas.

A avaliação do crescimento se baseia no fato de que, praticamente, toda a matéria acumulada ao longo do ciclo da planta resulta da atividade fotossintética. Desta forma, 
A.

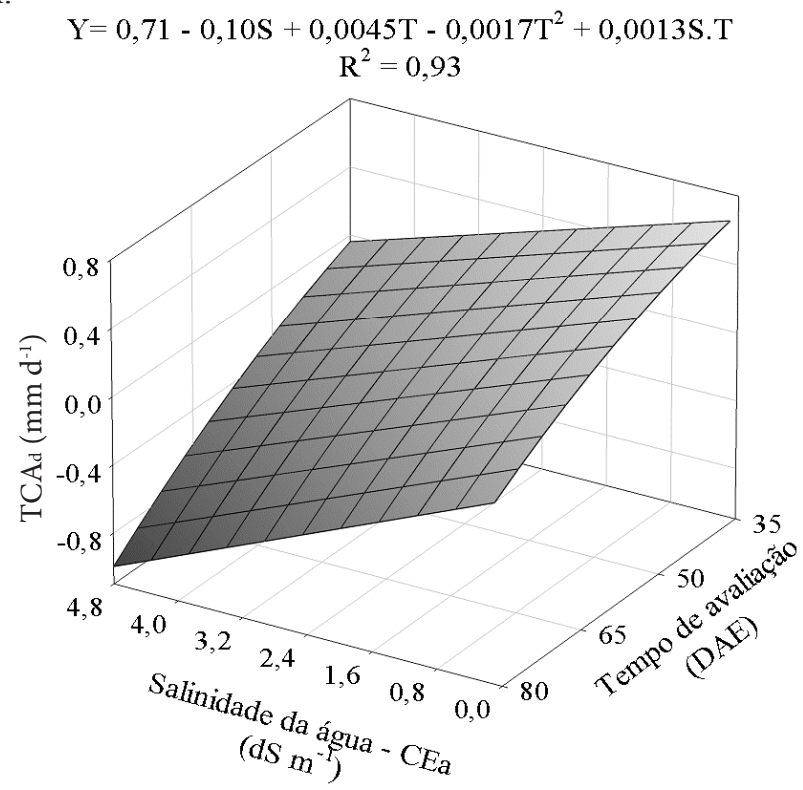

B.

$\mathrm{Y}=0,077-0,0026 \mathrm{~S}-0,0014 \mathrm{~T}+0,0000053 \mathrm{~T}^{2}+0,000035 \mathrm{~S} . \mathrm{T}$

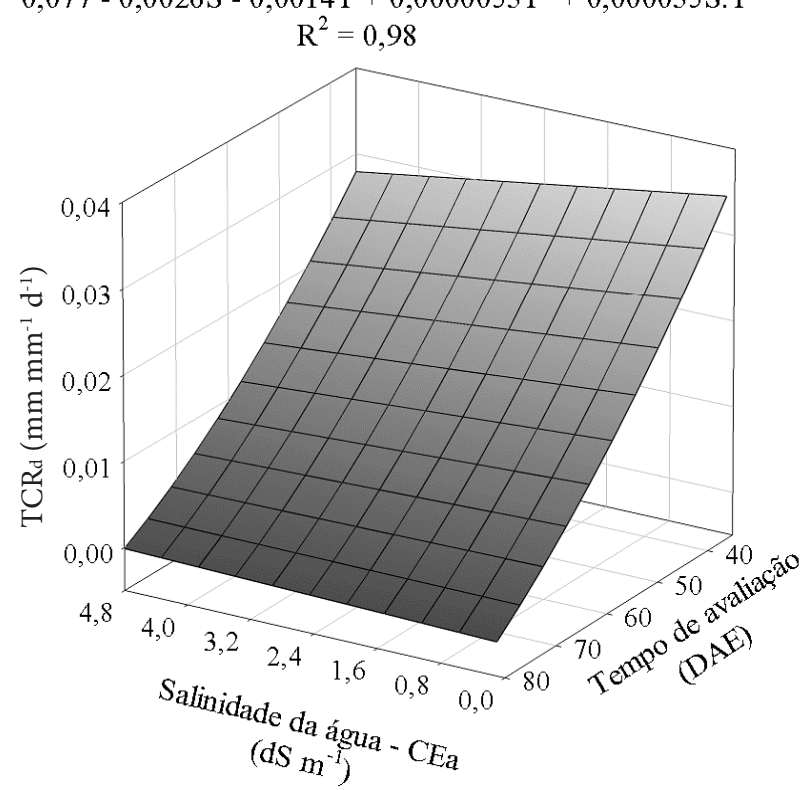

Figura 5. Valores médios da taxa de crescimento absoluto - $\mathrm{TCA}_{\mathrm{d}}(\mathrm{A})$ e relativo - $\mathrm{TCR}_{\mathrm{d}}(\mathrm{B})$ do diâmetro caulinar da mamoneira em diferentes tempos de crescimento e conteúdo de sais na água de irrigação

o acúmulo de matéria seca e o incremento da área foliar, quantificados em função do tempo, são utilizados na estimativa de vários índices fisiológicos relacionados às diferenças de desempenho entre cultivares. Normalmente, esses são: taxa de crescimento relativo, taxa assimilatória líquida, razão de área foliar, índice de área foliar, taxa de crescimento da cultura e índice de colheita (Lima et al., 2007). Os índices fisiológicos envolvidos e determinados na análise de crescimento indicam a capacidade do sistema assimilatório das plantas em sintetizar e alocar a matéria orgânica nos diversos órgãos que dependem da fotossíntese, respiração e translocação de fotoassimilados dos sítios de fixação aos locais de utilização ou de armazenamento (Fontes et al., 2005).
A.

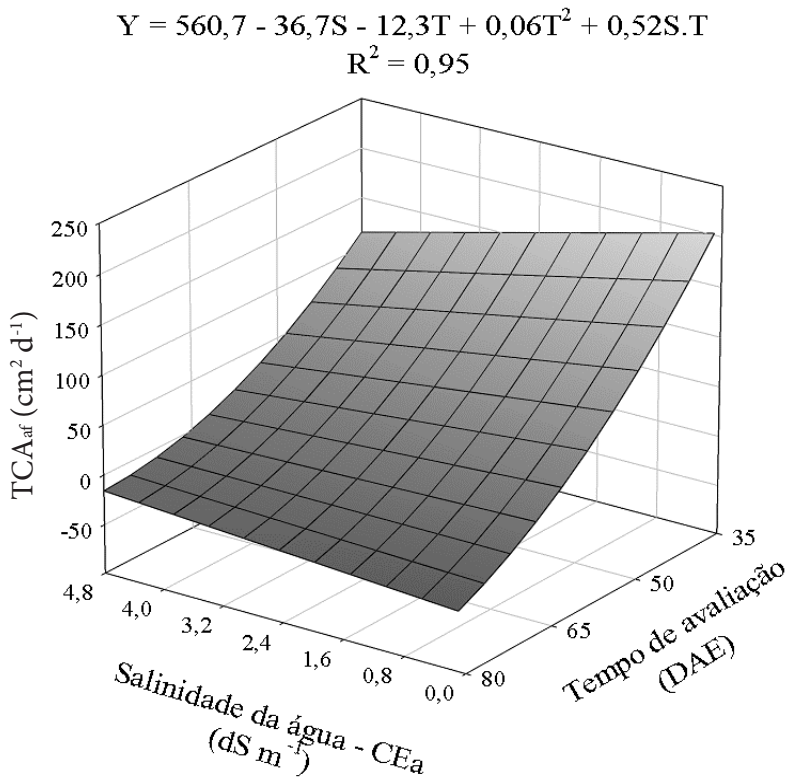

B.

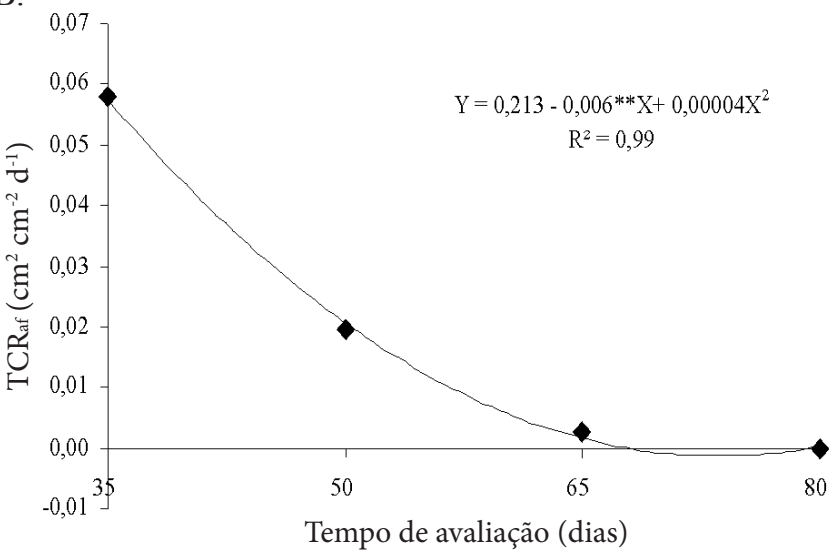

Figura 6. Taxa de crescimento absoluto - $\mathrm{TCA}_{\mathrm{af}}(\mathrm{A}) \mathrm{e}$ relativo $-\mathrm{TCR}_{\mathrm{af}}(\mathrm{B})$ de área foliar durante o crescimento da mamoneira irrigada com águas salinas

As inibições no crescimento em altura, diâmetro caulinar e área foliar com reflexos negativos na taxa de crescimento absoluto de cada respectiva variável, são resultado do aumento da salinidade do solo provocado pela irrigação com cada tipo de água. Pelos resultados da Figura 7, o solo estava, inicialmente, com condutividade elétrica do extrato de saturação - CEes de $0,71 \mathrm{dS} \mathrm{m}^{-1}$, na camada de $0-20 \mathrm{~cm}$ (Tabela 1 ) e, ao final do experimento, aos $80 \mathrm{DAE}$, foi elevada para 1,$15 ; 2,25 ; 4,21$; 4,71, 6,10 e 6,92 $\mathrm{dS} \mathrm{m}^{-1}$ acumulando aumentos de 62, 259, 493, 563,759 e $875 \%$ referentes ao solo irrigado com água de 0,12 ; 0,$80 ; 1,6 ; 2,4 ; 3,2 ; 4,0$ e $4,8 \mathrm{dS} \mathrm{m}^{-1}$. Os resultados, apesar de superiores ao adotado como ideal por Ayers \& Westcot (1999) em que a salinidade da água contribui com pelo menos $50 \%$ do acúmulo de sais aos solos, seriam bem maiores caso não se tivesse adotado a fração de lixiviação de $10 \%$ para a extração de parte dos sais do ambiente radicular das plantas.

O grau de salinidade do solo, de acordo com Richards (1954) foi incrementado de não salino (CEes $\left.<2 \mathrm{dS} \mathrm{m}^{-1}\right)$ quando irrigado com a água de $0,12 \mathrm{dS} \mathrm{m}^{-1}$ para ligeiramente salino (2 $\mathrm{dS} \mathrm{m} \mathrm{m}^{-1}<\mathrm{CEes}<4 \mathrm{dS} \mathrm{m}^{-1}$ ) sob irrigação com água de $0,8 \mathrm{dS}$ $\mathrm{m}^{-1}$. Verifica-se também que foi elevado para moderadamente 


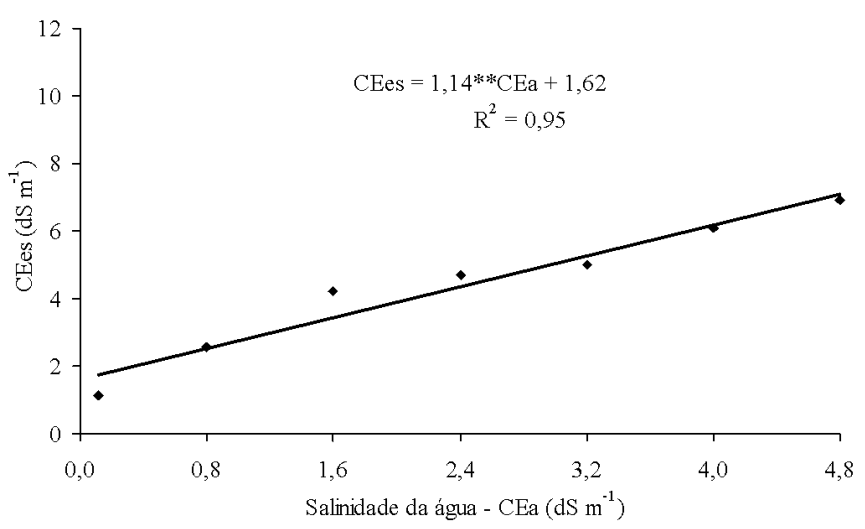

Figura 7. Condutividade elétrica do extrato de saturação na camada de $0-20 \mathrm{~cm}$ do solo em função da salinidade da água de irrigação, ao final do experimento

salino ( $6 \mathrm{dS} \mathrm{m}^{-1}>$ CEes $\left.>4 \mathrm{dS} \mathrm{m}^{-1}\right)$ com as águas de 1,6 e 2,4 $\mathrm{dS} \mathrm{m}^{-1} \mathrm{e}$, finalmente, para fortemente salino $\left(8 \mathrm{dS} \mathrm{m}^{-1}>\right.$ CEes $>6 \mathrm{dS} \mathrm{m}^{-1}$ ) quando irrigado com águas de 4,0 e 4,8 $\mathrm{dS} \mathrm{m}^{-1}$. Ao considerar que a mamoneira é moderadamente sensível à salinidade, isto significa que não tolera nível salino do solo acima de $3 \mathrm{dS} \mathrm{m}^{-1}$ sem perda do crescimento e da capacidade produtiva da cultura (Ayers \& Westcot, 1999).

\section{CONCLUSÕES}

1. Os efeitos degenerativos dos sais das águas ao crescimento em altura, diâmetro caulinar e à área foliar, aumentaram com a idade das plantas, após a emergência.

2. Apesar da inibição dos sais das águas, a mamoneira continuou crescendo até os 80 dias após a emergência das plântulas.

3. A maior agressividade dos sais foi registrada na área foliar da mamoneira BRS Energia.

4. A fração de lixiviação contribuiu para a manutenção do crescimento da mamoneira, mas o nível salino do solo foi elevado de não salino para fortemente salino, em função da salinidade das águas.

\section{Literatura Citada}

Ayers, R. S.; Westcot, D. W. A qualidade da água na agricultura. 2.ed. Campina Grande: UFPB. 1999, 218p. Estudos da FAO, Irrigação e Drenagem, 29

Babita, M., Maheswari, M.; Rao, L. M.; A. K.; Shanker, Rao, A. K.; Rao, D. G. 2010. Osmotic adjustment, drought tolerance and yield in castor (Ricinus communis L.) hybrids. Environmental and Experimental Botanic, v. 69, p.243-249, 2010.

Banzato, D. A.; Kronka, S. N. Experimentação agrícola. 4.ed. Jaboticabal: FUNEP, 2006. 237p.

Beltrão, N. E. M.; Vale, L. S.; Marques, L. F. ; Cardoso, G. D. Consórcio mamona e amendoim: Opção para a Agricultura Familiar.. Revista Verde de Agroecologia e Desenvolvimento Sustentável, v.5, p.222-227, 2010.

Benincasa, M. M. P. Análise de crescimento de plantas. Jaboticabal, FUNEP, 2003. 41p.
Campos, V. B.; Cavalcante, L. F.; Rodolfo Júnior, F.; Sousa, G. G.; Mota, J. K. M. Crescimento inicial da mamoneira em resposta à salinidade e biofertilizante bovino. Magistra, v. 21, p.041-047, 2009.

Cavalcanti, M. L. F.; Alves, A. N.; Gheyi, H. R.; Beltrão, N. E. de M.; Severino, L. S.; Soares, F. A. L. Desenvolvimento e produção de duas cultivares de mamoneira sob estresse salino. Revista Brasileira de Engenharia Agrícola e Ambiental, v.12, p.335-342, 2008.

Cavalcanti, M. L. F.; Fernandes, P. D.; Gheyi, H. R.; Barros Júnior, G.; Soares, F. A. L.; Siqueira, E. C. Índices ecofisiológicos da mamoneira sob estresse salino. Revista Brasileira de Engenharia Agrícola e Ambiental, v.9 (Suplemento), p.66-70, 2005a.

Cavalcanti, M. L. F.; Fernandes, P. D.; Gheyi, H. R.; Barros Júnior, G. Tolerância da mamoneira BRS 149 a salinidade, germinação e características de crescimento. Revista Brasileira de Engenharia Agrícola e Ambiental, v.9 (Suplemento), p.57-61, 2005b.

Centeno, C. R. M.; Azevedo, C. A. V. de; Santos, D. B. dos; Lira, V. M.; Santos, J. B. dos. Estimación de la evapotranspiración del rícino (Ricinus communis L.) cv. BRS energía regado com diferentes niveles de água salina. Agrociencia, v.42, p.321-331, 2012.

EMBRAPA - Empresa Brasileira de Pesquisa Agropecuária. Centro Nacional de Pesquisa de Solos. Manual e métodos de análises de solo. 2.ed. Rio de Janeiro: Embrapa CNPS 1997. 212p. Documentos, 1.

Fontes, P. C. R.; Dias, E. N.; Silva, D. J. H. Dinâmica do crescimento, distribuição de matéria seca na planta e produção de pimentão em ambiente protegido. Horticultura Brasileira, v.23, p.94-99, 2005.

Freire, A. L. O.; Sousa Filho, G. M.; Miranda, J. R. P.; Souto, P. C. S.; Araújo, L. V. C. Crescimento e nutrição mineral do nim (Azadirachta Indica A. Juss.) e cinamomo (Melia azedarach linn.) submetidos à salinidade. Ciência Florestal, v. 20, p.207-215, 2010.

Holanda, A. C.; Santos, R. V.; Souto, J. S.; Alves, A. R. Desenvolvimento inicial de espécies arbóreas em ambientes degradados por sais. Revista de Biologia e Ciências da Terra. v.7, p.39-50, 2007.

Lima, C. B.; Silva Filho, S. V.; Santos, M. A. dos.; Oliveira, M. de. Influência da àgua salina nas características físico-químicas do solo e no desenvolvimento da mamoneira cultivada em vasos. Revista Caatinga, v.20, p.132-136, 2007.

Lima, R. L. S.; Severino, L. S.; Sampaio, L. R.; Soffiati, V.; Gomes, J. A.; Beltrão, N. E. de M. Blends of castor meal and castor husks for otimized use as organic fertilizer. Industrial Crops and Products, v.58, p.232-237, 2011.

Marschiner, H. Mineral nutrition of higher plants, 6.ed. London: Academic Press. 2005. 621p.

Medeiros, J. F. de; Nascimento, I. B.; Gheyi, H. R. Manejo do solo-água-planta. In: Gheyi, H. R.; Dias, N. S.; Lacerda, C. F. (ed). Manejo da salinidade na agricultura: Estudos básicos e aplicados. Fortaleza: INCTSal. 2010, parte-IV, p.279-302 .

Mesquita, E. F.; Chaves, L . H. G.; Carvallo, H. O. G; Lacerda, R. D. Crescimento e produção de duas cultivares de mamoneira sob fertilização NPK. Revista Caatinga, v. 25, p.35-43, 2012. 
Nery, A. R.; Rodrigues, L. N.; Silva, M. B. R. da; Fernandes, P. D.; Chaves, L. H. G.; Dantas Neto, J.; Gheyi, H. R. Crescimento do pinhão-manso irrigado com águas salinas em ambiente protegido. Revista Brasileira de Engenharia Agrícola e Ambiental, v.13, p.551-558, 2009.

Nivas, D.; Goikwad, D. K.; Chavan, P. D.; Physiological responses of two Morinda species under saline conditions. American Journal of Plant Physiology, v.6, p.157-161, 2011.

Nunes, J. C.; Cavalcante, L. F.; Rebequi, A. M.; Lima Neto, A.; Diniz, A. A.; Silva, J. J. M.; Brehm, M. A. S. Formação de mudas de noni sob irrigação com águas salinas biofertilizante bovino no solo. Engenharia Ambiental, v.6, p.451-463, 2009.

Rhoades, J. D.; Kandiah, A.; Mashali, A. M.; Uso de águas salinas para produção agrícola. Campina Grande: UFPB. 2000. 117p. Estudos da FAO, Irrigação e Drenagem.

Rios, G. F. A.; Carvalho, L. G.; Magina, F. C.; Castro Neto, P.; Silva, B. M.; Fraga, A. C. Consumo hídrico e coeficiente de cultura da mamoneira na microrregião de Lavras, Minas Gerais. Revista Brasileira de Engenharia Agrícola e Ambiental, v.15, p.1275-1285, 2011.

Richards, L. A. Diagnóstico y reabilitacion de suelos salinos y sodicos. Departamento de Agricultura de los Estados Unidos da America. 5.ed. Mexico: Limusa, 1954. 172p (Manual de Agricultura, 60).
Santos, V. M.; Castro, H. G.; Cardoso, D. P.; Lima, S. O.; Leal, T. C. a. B.; Santos, G. R. Avaliação do crescimento e da produtividade da mamoneira BRS 149, Nordestina em dois níveis tecnológicos. Journal of Biotecnology and Biodiversity, v.2, p.58-66, 2011.

Severino, L. S.; Cardoso, G. D.; Vale, L. S.; Santos, J. W. Método para determinação da área foliar da mamoneira. Revista Brasileira de Oleaginosas e Fibrosas, v.8, p.753-762, 2004.

Silva, E. N.; Silveira, J. A. G.; Rodrigues, C. R. F.; Lima, C. S.; Viégas, R. A. Contribuição de solutos orgânicos e inorgânicos no ajustamento osmótico de pinhão-manso submetido à salinidade. Pesquisa Agropecuária Brasileira, v. 44, p.437-445, 2009.

Silva, S. M. S.; Alves, A. N.; Gheyi, H. R; Beltrão, N. E. de M.; Severino, L. S.; Soares, F. A. L. Desenvolvimento e produção de duas cultivares de mamoneira sob estresse salino. Revista Brasileira de Engenharia Agrícola e Ambiental, v.12, p.335-342, 2008.

Taherifard, E.; Farzad, G. Morphological characters of four varieties of castor beam (Ricinus communis) in responses to pruning lateral branches. Advances in Environmental Biology, v.5, p.3594-3598, 2011.

Veras, R. P.; Laime, E. M. O.; Fernandes, P. D.; Soares, F. A. L.; Freire, E. de A. Altura de planta, diâmetro caulinar e produção do pinhão-manso irrigado sob diferentes níveis de salinidade. Revista Brasileira de Engenharia Agrícola e Ambiental, v.15, p.582-587, 2011. 